\title{
Insoluble versus soluble polymer-assisted synthesis. A first approach for the preparation of a Biginelli compound
}

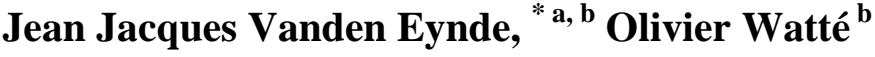 \\ ${ }^{a}$ Xavier University of Louisiana, College of Pharmacy, Division of Basic Pharmaceutical \\ Sciences, 1 Drexel Drive, New Orleans LA 70125, USA \\ ${ }^{b}$ University of Mons-Hainaut, Department of Organic Chemistry, Faculty of Sciences, \\ 20 Place du Parc, B-7000 Mons, Belgium \\ E-mail:jjvanden@xula.edu
}

\section{Dedicated to Professor Georges J. Hoornaert on his $65^{\text {th }}$ birthday}

(received 21 Feb 03; accepted 07 Apr 03; published on the web 09 Apr 03)

\begin{abstract}
A comparison is established between the experimental conditions associated with the multistep synthesis of ethyl 1,2,3,4-tetrahydro-6-methyl-2-oxo-4-phenylpyrimidine-5-carboxylate from Merrifield's resin and soluble polymers, derived from poly(ethylene glycol), poly(styrene-coallyl alcohol), or dendritic aliphatic polyols.
\end{abstract}

Keywords: Solid-phase synthesis, liquid-phase synthesis, dendrimer, pyrimidine, Biginelli

\section{Introduction}

Since the birth of combinatorial chemistry there has been an exploding interest in polymerassisted synthesis as the method generally yields final products in a high state of purity. Insoluble resins are often used because they are easy to handle. However long reaction times and excess of reagents are required to complete the reactions. Those drawbacks can readily be avoided by employing soluble polymeric auxiliaries. ${ }^{2}$ Nevertheless, that late approach remains underestimated probably because it is too often associated with the erroneous idea of the unpleasant manipulation of gummy products.

In a recent paper, ${ }^{3}$ we demonstrated that poly(styrene-co-allyl alcohol) is a suitable soluble support for the preparation of various nitrogen and oxygen heterocycles. We now wish to extend that work by disclosing our preliminary results on the solid-phase and liquid-phase synthesis of a member of the Biginelli compounds which are known to exhibit a broad range of biological effects. ${ }^{4}$ More particularly we focused our attention on a comparison between the experimental conditions associated with the use of each kind of supports. 


\section{Results and Discussion}

\section{Target compound}

Alkyl 1,2,3,4-tetrahydro-2-oxopyrimidine-5-carboxylates have been described by P. Biginelli ${ }^{5}$ more than a century ago. The original synthesis (Scheme 1) is a 3-component reaction involving urea, a ketoester, and an aldehyde under acidic conditions. ${ }^{6}$ Recently it has been observed that the resulting heterocycles can also be obtained through a solid-phase strategy (Scheme 1) involving condensation of a polymer bound thiouronium salt with an aralkylidene ketoester, followed by hydrolytic cleavage. ${ }^{7}$<smiles>[R]C=O</smiles><smiles>[R]OC(=O)CC([R])=O</smiles><smiles>[R]OC(=O)C1=C([R])NC(=O)N([R])C1([R])[2H]</smiles><smiles>CC</smiles><smiles>[R]OC(=O)C1=C([R])NC(SCOCC(C)C(C)C)=NC1([Z10])[Y]</smiles><smiles>[R]C=C(C([R7])=O)C([R])=O</smiles><smiles>CCC(CCCO)CCc1ccc(COc2ccc(CCl)cc2)cc1</smiles>

Scheme 1. Preparation of Biginelli Compounds. 
We selected the assisted multistep strategy to prepare ethyl 1,2,3,4-tetrahydro-6-methyl-2oxo-4-phenylpyrimidine-5-carboxylate (Figure1) from various supports.<smiles>CCOC(=O)C1=C(C)NC(=O)NC1c1ccccc1</smiles>

Figure 1. Structure of the target compound.

\section{Choice of the supports}

The most common insoluble 4-(chloromethyl)phenyl-containing polymer is the commercially available Merrifield's resin. In order to establish the proposed comparison we reasoned that 4(chloromethyl)phenyl moieties could be introduced on soluble matrices by reacting commercially available hydroxylated soluble polymers with 4-(chloromethyl)benzoic acid. For that purpose we directed our attention to the following three classes of supports: poly(ethylene glycol) (PEG), poly(styrene-co-allyl alcohol) (PSCAA), and dendritic aliphatic polyols of the Boltorn $^{\text {TM }}$ family. ${ }^{8}$

The chosen Merrifield's resin had a Cl content of $2.4 \mathrm{meq} / \mathrm{g}$. In the PEG series we selected three polymers having average molecular weights (average $M_{n}$ ) of 1500, 4600, and 10000 respectively and three poly(ethylene glycol) methyl ethers having average molecular weights of 750,2000 , and 5000 respectively. PSCAA had an average molecular weight of 2200. The average molecular weights of the dendritic polyols were 2100, 3500, and 5100 respectively. The corresponding hydroxyl indexes (meq/g) are collected in the Table. Among the reported values let us point out the impressive functionality of the Boltorn ${ }^{\mathrm{TM}}$ polymers, which bear 8.7-9.1 meq of hydroxyl groups per gram of material.

Esterification (Scheme 2) was performed in the presence of dicyclohexylcarbodiimide (DCC) and a catalytic amount of 4-(dimethylamino)pyridine (DMAP). Dichloromethane was chosen as the solvent except for the dendrimers, which are more soluble in dioxane.

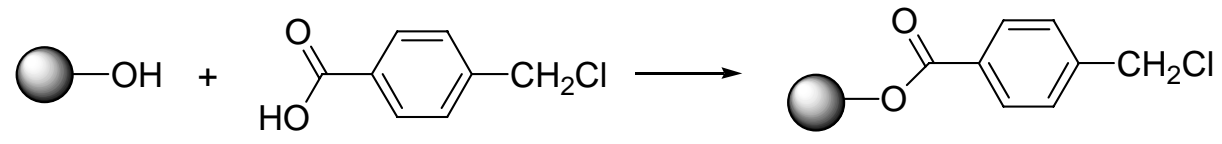

Scheme 2. Preparation of polymers bearing 4-(chloromethyl)phenyl Moieties.

In a first set of experiments we decided to perform the reactions at room temperature for 24 hours. After filtration of dicyclohexylurea (DCU), filtrates were concentrated under reduced pressure to afford the expected polymers as indicated by IR (carbonyl band at $1718 \mathrm{~cm}^{-1}$ ) and 
NMR ( ${ }^{1} \mathrm{H}$ NMR: $\delta \mathrm{CH}_{2} \mathrm{Cl}$ at $4.8 \mathrm{ppm} ;{ }^{13} \mathrm{C}$ NMR: $\delta \mathrm{C}=\mathrm{O}$ at $\left.165 \mathrm{ppm}\right)$. Due to the high value of the initial hydroxyl content of the dendrimers, the increase of weight of the polymers was also indicative of the success of the esterification. However let us emphasize that that increase of weight is associated with a dramatic decrease of their loading as it falls from $9 \mathrm{meq} / \mathrm{g}$ to $4 \mathrm{meq} / \mathrm{g}$. In order to optimize the experimental conditions, we determined that the theoretical amount of DCU precipitated out of the media after 4 hours of contact between the reagents. No remarkable structure dependence was detected.

Table 1. Characteristics of the polymers involved in the study

\begin{tabular}{|c|c|c|c|}
\hline Structure & Name & $\begin{array}{l}\text { Average } \\
\text { M.W. }\end{array}$ & $\begin{array}{c}\text { Loading } \\
\text { meq/g }\end{array}$ \\
\hline 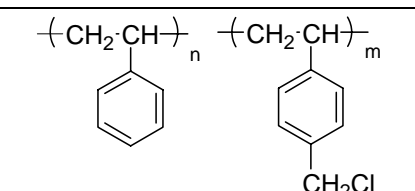 & $\begin{array}{l}\text { Merrifield's resin } \\
\text { Chloromethylated }\end{array}$ & & 2.4 \\
\hline \multirow{3}{*}{$\mathrm{HO}-\mathrm{CH}_{2} \cdot \mathrm{CH}_{2}\left(\mathrm{O}-\mathrm{CH}_{2} \cdot \mathrm{CH}_{2}\right) \mathrm{OH}$} & \multirow{3}{*}{$\begin{array}{l}\text { Poly(ethylene glycol) } \\
\text { PEG }\end{array}$} & 1500 & 1.3 \\
\hline & & 4600 & 0.4 \\
\hline & & 10000 & 0.2 \\
\hline \multirow{3}{*}{$\mathrm{H}_{3} \mathrm{CO}-\mathrm{CH}_{2} \cdot \mathrm{CH}_{2}\left(\mathrm{O}-\mathrm{CH}_{2} \cdot \mathrm{CH}_{2}\right) \mathrm{O}$} & \multirow{3}{*}{$\begin{array}{l}\text { Poly(ethylene glycol) } \\
\text { methyl ether } \\
\text { PEGME }\end{array}$} & 750 & 1.3 \\
\hline & & 2000 & 0.5 \\
\hline & & 5000 & 0.2 \\
\hline 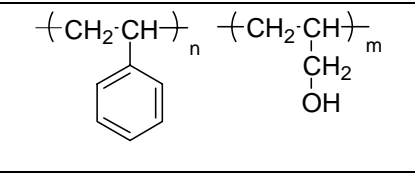 & $\begin{array}{l}\text { Poly(styrene-co-allyl } \\
\text { alcohol) } \\
\text { PSCAA }\end{array}$ & 2200 & 2.5 \\
\hline & $\begin{array}{l}\text { Boltorn }^{\mathrm{TM}} \mathrm{H} 20 \\
\mathrm{Y}=\mathrm{H}\end{array}$ & 2100 & 9.1 \\
\hline & Boltorn $_{\mathrm{Y}=}^{\mathrm{TM}} \mathrm{H} 30$ & 3500 & 8.7 \\
\hline
\end{tabular}




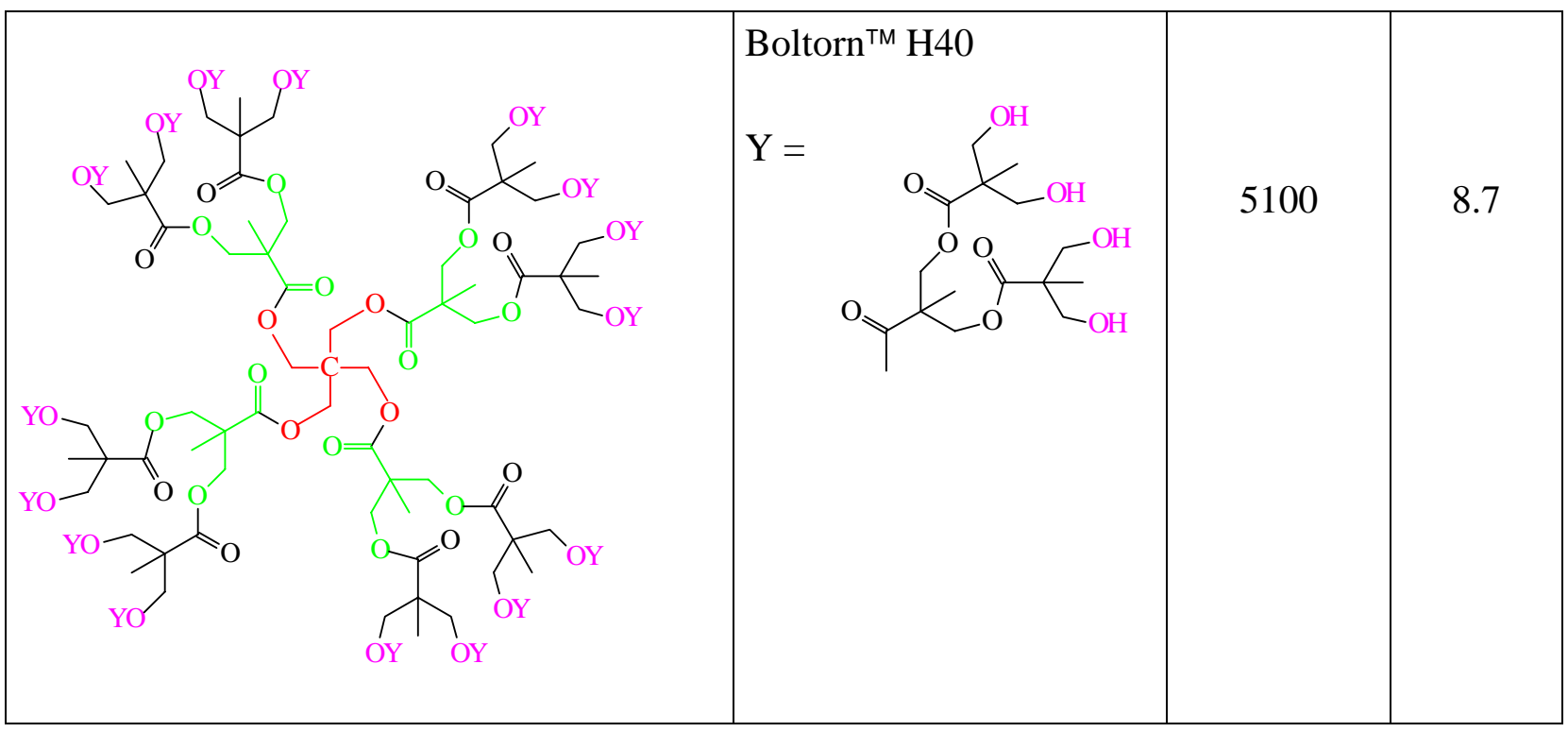

\section{Coupling with thiourea}

From Merrifield's resin we observed that the quantitative addition (no more spectral change, no more increase of weight) of thiourea could be achieved by refluxing a mixture of the resin and thiourea (5 equivalents) in dimethyl formamide (DMF) for 24 hours (Scheme 3). ${ }^{\text {7, } 9}$

Clearly, use of soluble polymers enables to decrease reaction times and does not require an excess of thiourea. All of them readily reacted in boiling ethanol and the thiouronium bound polymers were isolated after cooling and evaporation of the solvent. For the PEG and PEGME derivatives, an optimized contact period of 1 hour was determined by testing the media for the presence of thiourea with bismuth chloride. ${ }^{10}$ PSCAA-based polymer and dendrimers were entirely derivatized within 4 hours.

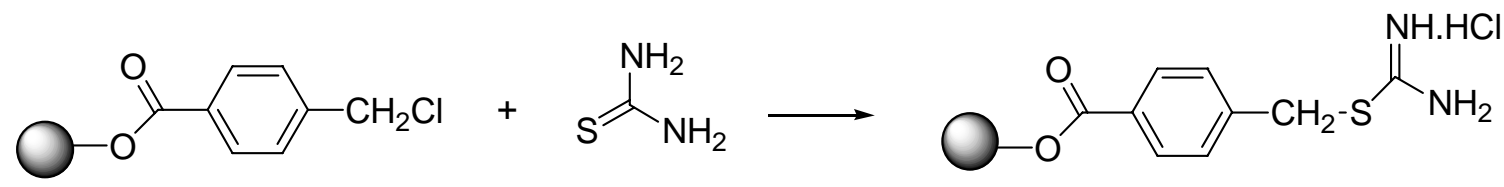

Scheme 3. Preparation of thiouronium polymers.

\section{Formation of the dihydropyrimidine skeleton}

In order to build the heterocyclic moiety, the thiouronium bound polymers were treated with ethyl 2-benzylidene-3-oxobutanoate in the presence of a base $\left(\mathrm{NaHCO}_{3}\right)$ (Scheme 4). ${ }^{7,11}$

From the insoluble polystyrene derivative the experiment was conducted with an excess of reagents (4 equivalents based on the announced initial content of $\mathrm{Cl}$ of the resin) in $\mathrm{DMF}$ at 100 ${ }^{0} \mathrm{C}$. The progress of the reaction was followed by IR (appearance of a carbonyl band at $1685 \mathrm{~cm}^{-}$ ${ }^{1}$ ). No more change of the spectrum of the resin was observed after 6 hours. 
From the soluble polymers the reactions were performed in boiling ethanol in the presence of one equivalent (calculated on the initial content of hydroxy groups) of the arylidene component and two equivalents of $\mathrm{NaHCO}_{3}$. By monitoring the reactions by GC we determined that a maximum amount (75 - $85 \%$ ) of ester was consumed within 4 hours independently of the nature of the polymer. Here again we did not determine any straightforward relationship between yields and the structure of the supports.

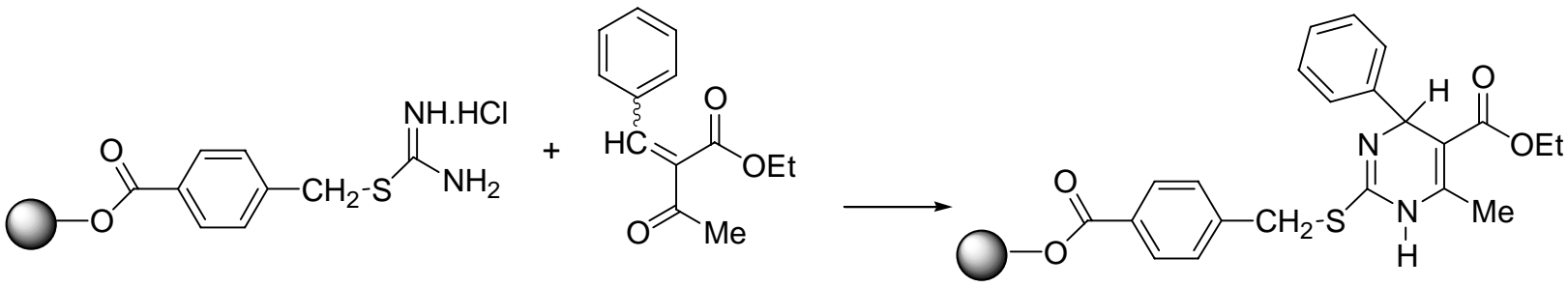

Scheme 4. Preparation of polymer-bound dihydropyrimidines.

\section{Cleavage from the support}

The final pyrimidine derivative was obtained by cleavage of the heterocycle from the support under the conditions described by Kappe: use of a refluxing mixture (volumes are given for $1 \mathrm{~g}$ of the starting resin) of dioxane $(10 \mathrm{~mL})$, ethanol $(10 \mathrm{~mL})$, acetic acid $(2 \mathrm{~mL})$, and water $(2 \mathrm{~mL})$ (Scheme 5). ${ }^{7}$ Under those conditions, the expected heterocycle is soluble in the mixture of solvents and can be isolated after concentration of the reaction medium.

From the insoluble resin we obtained the pyrimidine in an overall yield of $65 \%$ (based on the $\mathrm{Cl}$ content). An optimized refluxing period of 10 hours was determined, as experiments involving a prolonged heating did not improved the yield.

From the PEG- and PEGME-based polymers, the reaction media were heated under reflux for 4 hours (optimized). After concentration of the solution and treatment with water the heterocycle was isolated in overall yields (based on the $\mathrm{OH}$ content) ranging from 55 to $70 \%$. Reasonably we could not attribute the observed differences to structural changes of the supports. Under similar experimental conditions, the cleaved PSCAA-based polymer precipitated and was filtered. The filtrate was concentrated and the residue was treated with water to afford the pyrimidine in $60 \%$ overall yield (based on the $\mathrm{OH}$ content). Boltorn ${ }^{\mathrm{TM}}$-based polymers exhibited a similar behavior.

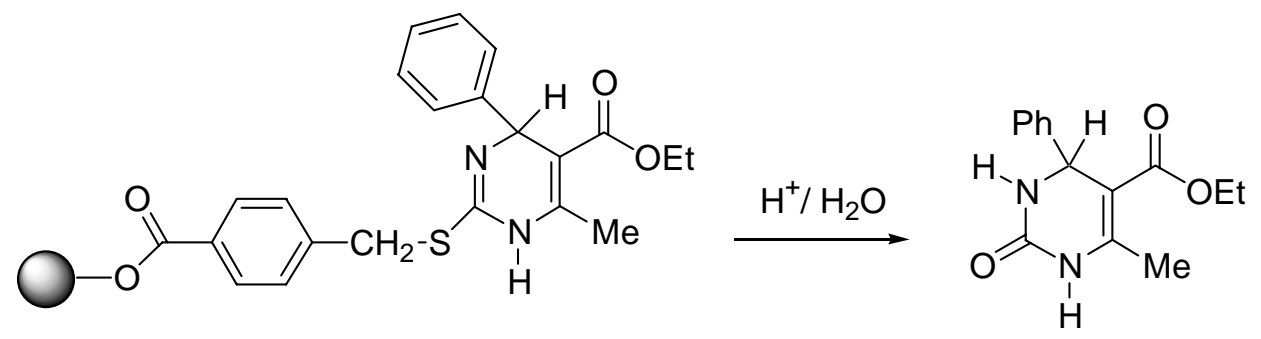


Scheme 5. Formation of the target compound by cleavage from the support.

\section{Conclusions}

This work compares the efficiency of an insoluble resin and a series of soluble polymers for the preparation of ethyl 1,2,3,4-tetrahydro-6-methyl-2-oxo-4-phenylpyrimidine-5-carboxylate. As expected use of soluble supports enables to reduce reaction times and does not require an excess of reagents. More interestingly from both types of polymers yields are comparable and in each family they do not seem to be dependent on the molecular weight of the starting polymers, thus enabling to take benefit of the macromolecular properties of each one. This work also demonstrates that protocols involving soluble polymers can readily be established and that such supports can reasonably compete with their insoluble counterparts which are often more expensive.

\section{Experimental Section}

General Procedures . ${ }^{1} \mathrm{H}$ and ${ }^{13} \mathrm{C}$ NMR spectra were obtained using a Bruker AMX-300 spectrometer (300 MHz for ${ }^{1} \mathrm{H}$ and $75 \mathrm{MHz}$ for ${ }^{13} \mathrm{C}$ at $7 \mathrm{~T}$ ); chemical shifts $(\delta)$ are given in ppm using TMS as internal reference. IR spectra were recorded on a Perkin-Elmer FTIR 1760K spectrometer. Solvents are commercially available (Aldrich Co, Acros Organics) and were used without further purification. PEGs and PEGMEs were dried by azeotropic distillation before use. For the soluble polymers, spectroscopic data collect the most striking information recorded in the case of the functionalization of a PEGME only, similar characteristics were observed from the other soluble auxiliaries.

Esterification of the hydroxylated soluble polymers. The polymers were esterified with theoretical stoichiometric amounts of 4-(chloromethyl)benzoic acid and dicyclohexylcarbodiimide in the presence of 4-dimethylaminopyridine $(10 \% \mathrm{~mol})$ in dichloromethane or dioxane $\left(5 \mathrm{~mL} / \mathrm{g}\right.$ of polymer; in the case of Boltorn ${ }^{\mathrm{TM}}$, the polymer was dissolved in hot dioxane and the solution was cooled down to rt before use). After $4 \mathrm{~h}$, dicyclohexylurea was filtered and the filtrate was concentrated under reduced pressure. The residue was washed with ether.

IR (KBr) : $1718(\mathrm{C}=\mathrm{O}) \mathrm{cm}^{-1} .{ }^{1} \mathrm{H}$ NMR (DMSO) : $4.8\left(\mathrm{CH}_{2}-\mathrm{Cl}\right) ; 7.2-8.1$ (Ar) ppm. ${ }^{13} \mathrm{C}$ NMR (DMSO): 45.2 ( $\left.\mathrm{CH}_{2}-\mathrm{Cl}\right) ; 128.0 ; 129.1 ; 129.5 ; 142.9 ; 165.3(\mathrm{C}=\mathrm{O}) \mathrm{ppm}$.

Coupling with thiourea. A mixture of Merrifield's resin (5 g) and thiourea (3.8 g, $50 \mathrm{mmol})$ in ethanol $(40 \mathrm{~mL})$ was heated under reflux for 24 hours. After cooling the resin was filtered and thoroughly washed with water and ethanol. 
IR (KBr) : 745; 1019; 1418; 1635; $3435 \mathrm{~cm}^{-1}$.

The soluble polymers were reacted with theoretical stoichiometric amounts of thiourea in boiling ethanol (5 mL/g of polymer; for reaction times see text). After cooling the mixture was concentrated under reduced pressure.

IR (KBr): $3208(\mathrm{~N}-\mathrm{H}) ; 3328(\mathrm{~N}-\mathrm{H}) \mathrm{cm}^{-1} .{ }^{1} \mathrm{H}$ NMR (DMSO) : $4.7\left(\mathrm{CH}_{2}-\mathrm{S}\right) ; 9.5(\mathrm{~N}-\mathrm{H})$ ppm. ${ }^{13} \mathrm{C}$ NMR (DMSO): $55.1\left(\mathrm{CH}_{2}-\mathrm{S}\right) ; 169.1(\mathrm{~S}-\mathrm{C}=\mathrm{NH}) \mathrm{ppm}$.

Formation of the dihydropyrimidine skeleton. The insoluble resin obtained above was treated with ethyl 3-phenyl-2-acetylpropenoate $(8.72 \mathrm{~g}, 40 \mathrm{mmol})$ and sodium hydrogenocarbonate (40 mmol) in hot dimethyl formamide $\left(100{ }^{\circ} \mathrm{C}\right)$ for 16 hours. After cooling the resin was filtered and thoroughly washed with water and ethanol.

IR (KBr): 696; 1149; 1648; $3367 \mathrm{~cm}^{-1}$.

The soluble polymers were reacted with theoretical stoichiometric amounts of ethyl 3phenyl-2-acetylpropenoate and a two-fold stoichiometric amount of sodium hydrogenocarbonate in boiling ethanol ( $5 \mathrm{~mL} / \mathrm{g}$ of polymer) for 4 hours. In the case of the PEG-based and PEGMEbased polymers, the solvent was evaporated under reduced pressure and the residue was extracted with dichloromethane; concentration of the organic layer yielded a paste that was precipitated with ether. In the case of the PSCAA-based and Boltorn ${ }^{\mathrm{TM}}$-based polymers, the precipitate was filtered and washed with alcohol.

IR (KBr): $1715(\mathrm{C}=\mathrm{O}) \mathrm{cm}^{-1} .{ }^{1} \mathrm{H}$ NMR : $1.1\left(\mathrm{O}-\mathrm{CH}_{2}-\mathrm{CH}_{3}\right) ; 3.9\left(\mathrm{O}-\mathrm{CH}_{2}-\right) ; 5.1\left(\mathrm{C}^{4}-\mathrm{H}\right) \mathrm{ppm}$.

Cleavage from the support. The insoluble resin obtained above was heated (10 hours) in a refluxing mixture of ethanol $(5 \mathrm{~mL})$, acetic acid $(2.5 \mathrm{~mL})$, water $(2.5 \mathrm{~mL})$, and dioxane $(5 \mathrm{~mL})$. After cooling, the resin was filtered and thoroughly washed with ethanol. The combined filtrates were concentrated under reduced pressure. Treatment of the residue with water afforded the expected heterocycle. It was identified by comparison with the data collected on a sample prepared by a reported classical procedure. ${ }^{5}$

The PEG-based or PEGME-based polymer (1 g) was heated for 4 hours in a refluxing mixture of ethanol $(1 \mathrm{~mL})$, acetic acid $(0.5 \mathrm{~mL})$, water $(0.5 \mathrm{~mL})$, and dioxane $(1 \mathrm{~mL})$. After cooling, the solution was concentrated under reduced pressure and the residue was treated with water to afford the expected heterocycle.

The PSCAA-based or Boltorn ${ }^{\mathrm{TM}}$-based polymer $(1 \mathrm{~g})$ was heated for 4 hours in a refluxing mixture of ethanol $(1 \mathrm{~mL})$, acetic acid $(0.5 \mathrm{~mL})$, water $(0.5 \mathrm{~mL})$, and dioxane $(1 \mathrm{~mL})$. After cooling, the precipitated polymer was filtered and the filtrate was concentrated under reduced pressure. The residue was treated with water to afford the expected heterocycle.

Data for the heterocycle. M.p. : $205-8{ }^{0} \mathrm{C}$. IR (KBr): 1091; 1220; 1650; 1699; 1725; 2978; 3117; $3245 \mathrm{~cm}^{-1} .{ }^{1} \mathrm{H}$ NMR (DMSO) : $1.1\left(\mathrm{O}-\mathrm{CH}_{2}-\mathrm{CH}_{3}\right) ; 2.3\left(\mathrm{C}^{6}-\mathrm{CH}_{3}\right) ; 3.9\left(\mathrm{O}-\mathrm{CH}_{2}\right)$; $5.2\left(\mathrm{C}^{4}-\mathrm{H}\right)$; $7.4\left(\mathrm{C}^{4}-\mathrm{Ph}\right) ; 7.8(\mathrm{NH}) ; 9.3(\mathrm{NH}) \mathrm{ppm}$.

\section{Acknowledgments}


The authors are grateful to Bo Pettersson (Perstorp Speciality Chemicals AB) for a gift of various samples of Boltorn ${ }^{\mathrm{TM}}$.

\section{References}

1. e.g. (a) Terret, N.K.; Gardner, M.; Gordon, D.W.; Kobylecki, R.J.; Steele, J. Tetrahedron 1995, 51, 8135. (b) Fruchtel, J.S.; Jung. G. Angew. Chem. Int. Ed. Engl. 1996, 35, 17. (c) Hermkens, P.H.H.; Opttenheijm, H.C.J.; Rees, D. Tetrahedron 1997, 53, 5643.

2. e.g. (a) Bonara, G.M. Applied Biochem. Biotech. 1995, 54, 3. (b) Gravert, D.J.; Janda, K.D. Chem. Rev. 1997, 97, 489.

3. Vanden Eynde, J.J.; Rutot, D. Tetrahedron 1999, 55, 2687.

4. Kappe, C.O. Eur. J. Med. Chem. 2000, 35, 1043.

5. Biginelli, P. Gazz. Chim. Ital. 1893, 23, 360.

6. Kappe, C.O. Tetrahedron 1993, 49, 6937.

7. Kappe, C.O. Bioorg. Med. Chem. Lett. 2000, 10, 49.

8. Kantchev, A.B.; Parquette, J.R. Tetrahedron Lett. 1999, 40, 8049.

9. Obrecht, D.; Abrecht, C.; Grieder, A.; Villigordo, J.M. Helv. Chim. Acta 1997, 80, 65.

10. Charlot, G. in Les Méthodes de la Chimie Analytique Ed. Masson (Paris, France), 1966.

11. Milcent, R.; Malanda, J.-C.; Barbier, G.; Vaissermann, J. J. Heterocycl. Chem. 1997, 34, 329. 